\section{Vitamin D Usage among Pakis- tani Population - Too Much of a Good Thing}

Sir,

Vitamin D deficiency (VDD) is one of the most common nutritional disorders worldwide. This is also true in Pakistan as reported by Riaz and colleagues in their study, revealing VDD in $53.5 \%$ and insufficiency in $31.2 \%$ study participants. ${ }^{1}$ There is growing awareness of VDD in the Pakistani population, which has resulted in vitamin $D$ becoming a popular supplement in the community and is being used as one of the most common over the counter medicines. It is also being prescribed more frequently by physicians; with supplements ranging from vitamin D capsules to high dose $(50,000 \mathrm{IU}, 200,000 \mathrm{IU}$, and $600,000 \mathrm{IU})$ injections. Sometimes, these are continued for indefinite periods without baseline checking or follow-up monitoring of 25-OH vitamin D levels.

As a result of this increased consumption of vitamin D supplements by the general population and overcorrection of VDD by some healthcare practitioners, it is becoming a leading cause of hypervitaminosis D and hypercalcemia, also called as vitamin D toxicity (VDT). ${ }^{2,3}$ In literature, VDT has been reported from various parts of the world to be associated with significant morbidity and mortality. ${ }^{4}$ We are also witnessing many patients referred to our clinics and also as inpatient with VDT and serious problems. The true prevalence of VDT in the Pakistani population is not known so far, but is not uncommon, as reported by Khan et $a l ;{ }^{5} 27 \%$ of their patients with hypercalcemia were found to have VDT, where multiple high dose injections were given weekly to these patients for six to eight weeks. ${ }^{5}$ Our intent in sending this communication is to help create awareness amongst health professionals regarding VDT and appropriate replacement of vitamin D based on baseline $25-\mathrm{OH}$ vitamin D levels, age and associated risk factors. Furthermore, general public should also be educated about the toxic consequences of this over the counter medicine.

\section{CONFLICT OF INTEREST:}

The authors declared no conflict of interest.

\section{AUTHORS' CONTRIBUTION:}

BD: Came up with idea to write this letter and design it.

SN: Revised it critically and approved final version to be published.

\section{REFERENCES}

1. Riaz H, Finlayson A, Bashir S, Hussain S, Mahmood S, Malik $F$, et al. Prevalence of vitamin d deficiency in pakistan and implications for the future. Expert Rev Clin Pharmacol 2016; 9(2):329-38.

2. Dudenkov DV, Yawn BP, Oberhelman SS, Fischer PR, Singh RJ, Cha'SS, et al. 'Changing incidence of serum' 25-hydroxyvitamin D values above $50 \mathrm{ng} / \mathrm{mL}$ : A 10-year population-based study. Mayo Clin Proc 2015; 90(5): 577-86.

3. Tebben PJ, Singh RJ, Kumar R. Vitamin D-mediated hypercalcemia: Mechanisms, diagnosis, and treatment. Endocr Rev 2016; 37(5):521-47.

4. Galior K, Grebe S, Singh R. Development of vitamin D toxicity from overcorrection of vitamin D deficiency: A review of case reports. Nutrients 2018; 10(8):953.

5. Khan MN, Masood MQ, Siddiqui MA, Naz S, Islam N. Vitamin-D toxicity and other non-malignant causes of hypercalcemia: A retrospective study at a tertiary care hospital in Pakistan. JAMC 2017; 29(3):436-40.

Bhagwan Das and Sarah Nadeem

The Aga Khan University Hospital, Karachi, Pakistan

Correspondence to: Dr. Bhagwan Das, Section of Endocrinology, Department of Medicine, The Aga Khan University Hospital, Stadium Road, Karachi, Pakistan

E-mail:dr_bhagwandas@yahoo.com

Received: November 20, 2019; Revised: January 27, 2020; Accepted: January 27, 2020

DOI: https://doi.org/10.29271/jcpsp.2020.09.1002 